\title{
Pelatihan dan Pembuatan Lembar Kerja Siswa pada (Applet) Geogebra Online
}

\author{
Windia Hadi ${ }^{1 *}$, Isnaini Handayani ${ }^{1}$ \\ ${ }^{1}$ Pendidikan Matematika, Universitas Muhammadiyah Prof. DR. HAMKA, Jalan Tanah Merdeka, Jakarta Timur, DKI \\ Jakarta, Indonesia 13830
}

*Email koresponden: windia.hadi@uhamka.ac.id

\section{ARTICLE INFO}

Article history

Received: 28 Agst 2020

Accepted: 25 Mar 2021

Published: 23 Apr 2021

\section{Kata kunci:}

Applet

Bahan Ajar Matematika

Geogebra

Soft Skill

Lembar Kerja Siswa

\author{
Keyword: \\ Applets \\ Geogebra \\ Mathematics Teaching \\ Materials \\ Student Worksheets
}

\begin{abstract}
A B S T R A K
Background: Matematika merupakan mata pelajaran yang selalu tidak disukai oleh sebagian besar siswa karena materinya abstrak dan juga rumit karena banyaknya rumus yang digunakan dalam menyelesaikan masalah. Tugas seorang guru matematika adalah bagaimana membuat siswa menyukai matematika dan dengan mudah memahami materi yang telah diberikan kepada guru, pada saat pandemi Covid-19 sekolah belajar secara online, dimana siswa belajar di rumah menggunakan LMS yang ada. Guru matematika harus memiliki keterampilan dalam merancang bahan ajar dan LKS untuk proses belajar mengajar. Kegiatan pelatihan ini untuk membantu guru matematika dalam membuat bahan ajar dan membuat LKS siswa menggunakan GeoGebra secara online, dengan tujuan agar pengajar dapat membuat bahan ajar dan LKS dalam proses belajar mengajar. Metode: Pelatihan ini dilaksanakan pada Rabu, 12, dan 19 Agustus 2020. Dalam kegiatan pendampingan melibatkan 114 guru matematika se-Jakarta Timur dengan tiga narasumber, termasuk dua dosen dari FKIP Prof. DR. HAMKA dan salah satu dosen FIP, Universitas PGRI Semarang. Hasil: Hasil penelitian menunjukkan bahwa guru sangat antusias dalam pelatihan pembuatan bahan ajar dan lembar kerja siswa (applet) pada GeoGebra, selain itu guru sangat bersemangat dalam membuat bahan ajar walaupun guru belum pernah menggunakan GeoGebra sebelumnya di Saat belajar matematika di sekolah, kekurangannya adalah guru belum menguasai alat GeoGebra. Kesimpulan: Mereka membuatnya menantang untuk menggambar sesuai keinginan mereka.
\end{abstract}$$
\text { A B S T R A C T }
$$

Background: Mathematics is a subject that is always disliked by most students because the material is abstract and also tricky because of the many formulas used in solving problems. The task of a math teacher is how to make students like mathematics and easily understand the material that has been given to the teacher, during the Covid-19 pandemic, schools are learning online, where students study at home using existing LMS. Mathematics teachers must have skills in designing teaching materials and student worksheets for the teaching and learning process. This training activity is to help mathematics teachers in making teaching materials and making student worksheets using online GeoGebra, with the aim that teachers can make teaching materials and student worksheets in the teaching and learning process. Methods: This training was held on Wednesday, 12, and 19 August 2020. In mentoring activities, it involved 114 mathematics teachers from the East Jakarta area with three resource persons, including two lecturers from FKIP Prof. DR. HAMKA and one lecturer from FIP, PGRI University Semarang. Results: The results showed of the training show that the teacher is very enthusiastic in the training of making teaching materials and student worksheets (applets) on GeoGebra, add on the teacher is very excited in creating teaching materials even though the teacher has never used GeoGebra before in learning mathematics at school, the drawback is that the teacher has not mastered GeoGebra tools. Conclusions: They are making it challenging to draw according to their wishes
\end{abstract}




\section{PENDAHULUAN}

Di tengah wabah pandemi Covid-19 yang melanda dunia khususnya Indonesia saat ini, sistem pendidikan dihadapkan dengan situasi yang menuntut para pengajar untuk dapat menguasai media pembelajaran jarak jauh. Sistem pendidikan jarak jauh menjadi salah satu solusi untuk mengatasi kesulitan dalam pembelajaran secara langsung dengan adanya aturan social distancing mengingat permasalahan waktu, lokasi, jarak dan biaya yang menjadi kendala besar saat ini. Pendidikan jarak jauh, saat ini hampir semua para pelaku pendidikan menjadikannya salah satu solusi pembelajaran dalam menghadapi situasi wabah Pandemi Covid-19. Istilah pendidikan jarak jauh tersebut sudah lama digaungkan bahkan diterapkan oleh para pendidik maupun peserta didik dalam suatu proses pembelajaran yang notabene dalam hal ini lebih banyak dilakukan secara terpisah di luar kelas. Secara terpisah di sini berarti antara intruktur atau narasumber dan peserta pelatihan tidak berada dalam satu ruangan yang sama (tidak terjadi melakukan face to face) bahkan waktunya pun bisa berbeda (Muhson, 2010).

Dalam pengembangannya saat ini sudah banyak bermunculan aplikasi-aplikasi yang khusus digunakan sebagai media untuk melakukan pembelajaran jarak jauh ada Zoom, Whatsapp, Schoology, dan lainnya. Namun, dalam pembelajaran matematika pembelajaran jarak jauh menjadi kendala dikarenakan matematika merupakan symbol yang abstrak dan susah dideskripsikan melalui pembelajaran jarak jauh (Putrawansyah et al., 2016). Pembelajaran matematika lebih jelas dan baik digunakan Ketika pembelajaran tatap muka berlangsung sehingga guru langsung memahami betul siswa yang belum memahami dengan siswa yang sudah memahami konsep yang telah diajarkan oleh guru mereka (Nasrulloh \& Ismail, 2018). Sedangkan untuk pembelajaran jarak jauh banyak siswa yang mengeluhkan bagaimana susahnya mengerjakan tugas matematika karena dengan pembelajaran jarak jauh guru hanya memberikan serangkaian tugas tanpa harus menjelaskannya materi sehingga menjadikan siswa makin sulit dalam pembelajaran matematika. Pembelajaran daring merupakan sebuah inovasi pendidikan yang melibatkan unsur teknologi informasi dalam pembelajaran. Menurut (Mustofa et al., 2019) bahwa Pembelajaran daring merupakan sistem pendidikan jarak jauh dengan sekumpulan metoda pengajaran dimana terdapat aktivitas pengajaran yang dilaksanakan secara terpisah dari aktivitas belajar. pembelajaran daring diselenggarakan melalui jejaring internet dan web 2.0 (Alessandro, 2018), artinya bahwa penggunaan pembelajaran daring melibatkan unsur teknologi sebagai sarana dan jaringan internet sebagai sistem. Pembelajaran daring telah banyak dilakukan dalam konteks perguruan tinggi, terbukti dari beberapa penelitian yang menjelaskan hal tersebut (Crews \& Parker, 2017; Mather \& Sarkans, 2018), pembelajaran daring memberikan manfaat dalam membantu menyediakan akses belajar bagi semua orang, sehingga menghapus hambatan secara fisik sebagai faktor untuk belajar dalam ruang lingkup kelas (Riaz, 2018), bahkan hal tersebut dipandang sebagai sesuatu yang efektif untuk diterapkan khususnya dalam perguruan tinggi, akan tetapi menurut (Pilkington, 2018) tidak bisa dipungkiri bahwa tidak semua pembelajaran dapat dipindahkan ke dalam lingkungan pembelajaran secara online(Darmayanti et al., 2013). 


\section{MASALAH}

Berdasarkan hasil observasi dalam kegiatan webinar banyak guru yang mengeluhkan bagaimana susahnya para guru matematika memberikan pemahaman konsep materi kepada siswa melalui pembelajaran jarak jauh, serta banyaknya keluhan siswa dalam menyelesaikan tugas yang diberikan guru melalui aplikasi pembelajaran jarak jauh yang digunakan. Hal ini yang menjadi permasalahan bagaimana mensiasati guru dan siswa agar mereka menikmati belajar matematika tanpa harus terbebani dengan adanya wabah covid-19 ini.

Permasalahan dan dampak harus segera diatasi dengan memberikan pemahaman yang utuh kepada guru matematika di Jakarta khususnya di Jakarta Timur sehingga mengharuskan guru matematika untuk lebih kreatif menciptakan ide dalam pembelajaran di kelas melalui pembelajaran jarak jauh karena jumlah yang terkena positif covid-19 yang tiap hari terus meningkat jumlah nya sehingga tidak mengetahui sampai berapa lama pembelajaran jarak jauh terus dilakukan. Adanya pembaharuan yang dilakukan guru dalam menciptakan belajar matematika dengan nyaman tanpa siswa kesulitan memahami konsep matematika tidak mudah butuh kerja keras dari guru matematika untuk terus berekspolasi, mengembangkan kemampuannya dalam memberikan ilmu yang terbaik kepada siswa sehingga siswa tidak bosan dalam pembelajaran jarak jauh.

\section{METODE PELAKSANAAN}

Pengabdian Masyarakat ini dilaksanakan secara daring dengan tema pelatihan penggunaan dan pembuatan lembar kerja siswa (applet) pada geogebra online. Webinar ini menggunakan aplikasi Zoom Meeting. Waktu pengabdian dilaksanakan pada bulan Agustus 2020 sebanyak 2 pertemuan yaitu pada Rabu, 12 Agustus 2020 dan Rabu, 19 Agustus 2020. Metode yang digunakan dalam penelitian ini adalah metode survei untuk mengetahui dan menganalisis hasil atau dampak terhadap guru-guru SMP/MTs/Sederajat terhadap pelatihan penggunaan dan pembuatan lembar kerja siswa (applet) pada geogebra online. Populasi dari penelitian ini adalah seluruh guru SMP/MTS/Sederajat seDKI Jakarta. Instrumen dalam penelitian ini terdiri dari angket yang diberikan sebelum dan setelah mengkuti pelatihan. Adapun analisis data dilakukan dengan mengolah data angket, kemudian membandingkan data sebelum dan sesudah mengikuti pelatihan.

Adapun langkah dalam pelaksanaan pengabdian ini yakni:

a. Ketua tim pengabdian menghubungi ketua MGMP Jakarta Timur Wilayah II dengan maksud dan tujuan untuk mengadakan pelatihan geogebra secara daring

b. Pihak MGMP menyetujui kemudian membentuk kepanitiaan serta membuat kesepakatan waktu dan susunan acara

c. Pihak MGMP bertugas membuat surat undangan, flyer, form pendaftaran peserta.

d. Tim Pengabdian menyiapkan narasumber dan materi pelatihan, serta sertfikat untuk peserta

e. Mahasiswa berperan mengatur serta mengkondisikan peserta webinar dan pemberian angket melalui google form dalam masukan serta kritik dalam pelatihan ini

f. Alumni berperan sebagai koordinator pelaksana kegiatan pelatihan ini

Dalam kegiatan ini, terdapat 3 (tiga) narasumber yang terlibat dengan masing-masing tugas: pembicara pertama menjelaskan dan melatih dalam penggunaan tools pada geogebra online, 
pembicara kedua menjelaskan dan melatih guru dalam membuat lembar kerja siswa yaitu dengan applet pada geogebra online, dan pembicara ketiga sebagai fasilitator dalam pembuatan applet. Kegiatan ini dilakukan dua kali pertemuan dengan durasi 4 jam/pertemuan dimana hari pertama (pekan pertama) adalah pemberian pretes serta tutorial atau penjelasan dan pertemuan kedua (pekan kedua) adalah presentasi dan praktik guru dalam membuat materi dan lembar kerja siswa serta pemberian postes. Peserta diberi waktu 1 (satu) minggu untuk membuat applet dengan menggunakan kelas online (google classroom) yang telah disiapkan narasumber. Pada tahap pendampingan belajar, setiap guru disegarkan ingatannya berkenaan dengan materi yang dibutuhkan untuk bisa menyelesaikan pembuatan materi.

\section{HASIL DAN PEMBAHASAN}

\section{Sosialisasi dan Pelatihan}

Sebelum kegiatan sosialisasi dan pelatihan guru matematika SMP dimulai, acara diawali dengan pembukaan kegiatan pengabdian kepada masyarakat yang dibuka oleh Ketua MGMP Matematika SMP Jakarta Timur Wilayah II, dan peserta Guru Matematika SMP se-Jakarta Timur sebanyak 114 Orang.

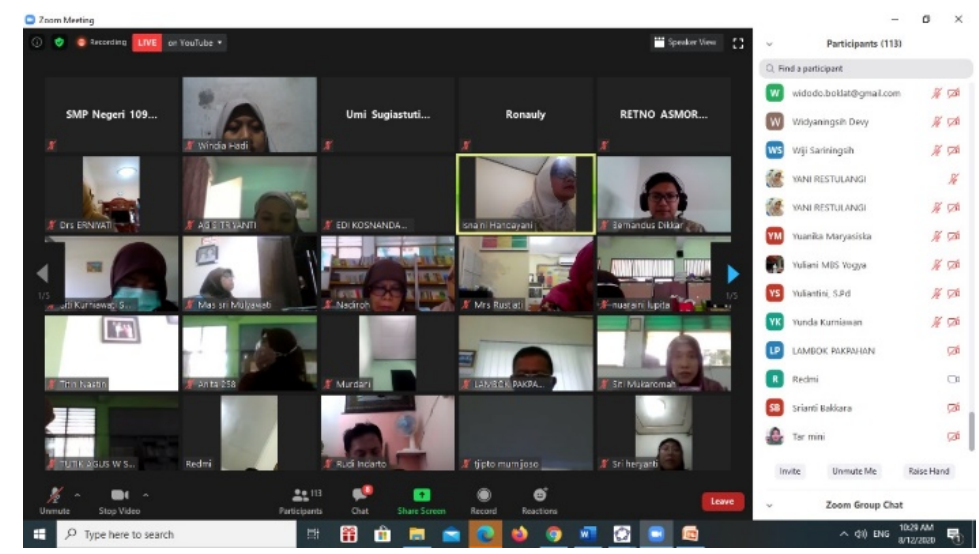

Gambar 1. Data Peserta yang mengikuti Pelatihan

Pelatihan pada hari pertama terdiri dari dua sesi, sesi pertama dimulai dengan narasumber Windia Hadi, M.Pd. \& Isnaini Handayani, M.Pd. yang merupakan pengguna Geogebra online dalam pembelajaran Geometri di Universitas Muhammadiyah Prof. DR. HAMKA dengan judul materi adalah 1. Paparan tentang aplikasi geogebra dan penggunaannya dalam pembelajaran matematika, 2. Pengenalan geogebra fitur dan tools secara umum yang dimoderatori oleh Dwi Kartika Avianty, M.Pd. (Guru matematika di SMP Negeri 237 Jakarta). Pada sesi sesi kedua pelatihan pembuatan Applet Geogebra Online yang di pandu oleh Instruktur Dr. Bagus Ardi Saputro, M.Pd dari Universitas PGRI Semarang yang dimoderatori oleh Siti Mukaromah, S.Pd. selaku guru matematika di MTs N 33 Jakarta. Pada pertemuan pertama, peserta diberi tugas selama 1 (satu) minggu untuk membuat applet secara mandiri, dan di upload di kelas online (google classroom) yang telah disediakan oleh instruktur. Kemudian instruktur akan mengomentari dan memberikan masukan terkait applet yang telah dibuat.

Pertemuan kedua, guru matematika yang telah mengirimkan hasil kerjanya melalui google classroom di cek dan diperiksa secara detail oleh instruktur Dr. Bagus Ardi Saputro, M.Pd. 
selanjutnya dipilih beberapa guru untuk mempresentasikan hasil appletnya melalui presentasi. Ada 2 peserta guru matematika yang mempresentasikan hasil kerjanya dengan menggunakan geogebra online.

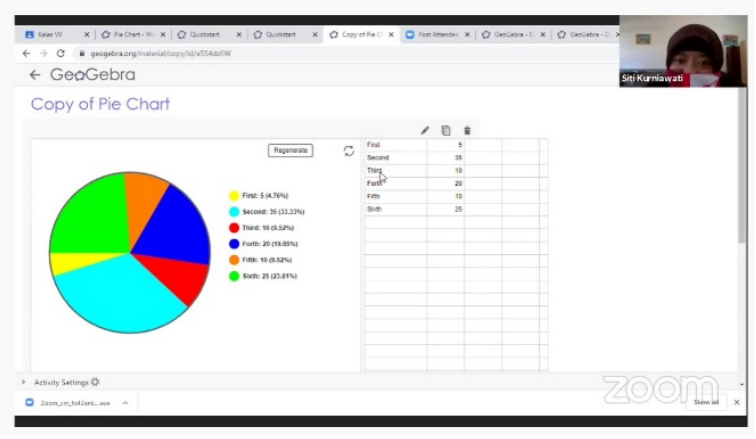

A

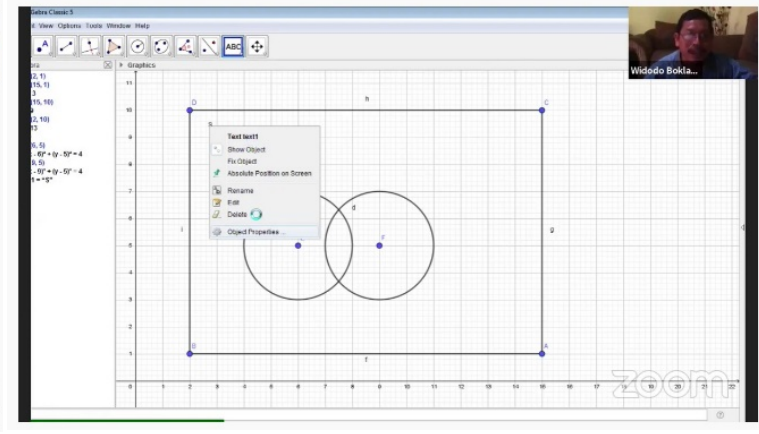

$\mathrm{B}$

Gambar 2. Hasil Presentasi Geogebra Online oleh Guru Matematika

Pada Gambar 2 merupakan hasil presentasi dari guru matematika dalam membuat lembar kerja siswa menggunakan geogebra online. Pada gambar 2A hasil presentasi yang dilakukan oleh guru matematika bernama Siti Kurniawati, beliau menjelaskan materi terkait diagram pie chat dengan menggunakan geogebra online, sedangkan pada Gambar 2B seorang guru matematika bernama Widodo menjelaskan tentang materi himpunan dengan menggunakan geogebra online.

Hasil dari pelatihan ini adalah peserta sangat antusias dilihat dari hasil evaluasi, dalam mengikuti materi pelatihan yang disampaikan oleh narasumber karena informasi baru dalam penggunaan tools serta pembuatan lembar kerja siswa menggunakan geogebra online karena sebelumnya guru matematika hanya menggunakan LMS google Classroom dimasa Pandemi Covid-19 dalam menyampaikan materi matematika. Beberapa saran dan masukan dari peserta mengenai kegiatan pelatihan ini antara lain :

1. Adanya pelatihan berkelanjutan untuk guru matematika SMP dan diadakan juga untuk guru matematika SMA.

2. Pelatihan ini sangat bagus dan sangat membantu para guru matematika dalam mengaplikasikan pembelajaran lewat IT.

3. Pelatihannya sudah baik dan menyenangkan

4. Sangat bermanfaat bagi guru matematika

Selanjutnya analisis dilakukan pada hasil instrumen angket yang berkaitan dengan materi pelatihan dan penyampaian narasumber seperti Nampak pada Tabel 1.

Tabel 1. Presentase Respon Peserta Mengenai Pelatihan

\begin{tabular}{llllll}
\hline \multicolumn{1}{c}{ Pernyataan } & \multicolumn{3}{c}{ Respon } & & \\
\hline & $\begin{array}{c}\text { Sangat } \\
\text { Setuju }\end{array}$ & Setuju & $\begin{array}{c}\text { Kurang } \\
\text { Setuju }\end{array}$ & $\begin{array}{c}\text { Tidak } \\
\text { Setuju }\end{array}$ \\
\hline Materi Pelatihan sangat banyak dan padat & 57,5 & 35 & 5 & 2,5 \\
Penyampaian materi cukup menarik dan tidak & 62,5 & 32,5 & 5 & 0
\end{tabular}




\begin{tabular}{llccc}
\hline $\begin{array}{l}\text { membosankan } \\
\begin{array}{l}\text { Materi pelatihan sesuai dengan materi } \\
\text { pembelajaran matematika }\end{array}\end{array}$ & 20 & 0 & 0 \\
$\begin{array}{l}\text { Penyampaian materi melalui Aplikasi ZOOM } \\
\text { cukup menyenangkan }\end{array}$ & 50 & 15 & 0 \\
$\begin{array}{l}\text { Waktu pelatihan terlalu singkat sehingga } \\
\text { banyak materi yang tidak dipahami }\end{array}$ & 40 & 25 & 5 \\
$\begin{array}{l}\text { Penguasaan materi dari para pembicara sudah } \\
\text { baik }\end{array}$ & 67,5 & 25 & 7,5 & 0 \\
$\begin{array}{l}\text { Latihan soal yang diberikan terlalu banyak dan } \\
\text { menyita waktu }\end{array}$ & 12,5 & 32,5 & 40 & 15 \\
$\begin{array}{l}\text { Pendampingan para pelatih terhadap peserta } \\
\text { dalam praktik sudah baik }\end{array}$ & 55 & 35 & 10 & 0 \\
$\begin{array}{l}\text { Praktik atau latihan yang diberikan kepada para } \\
\text { peserta masih sedikit }\end{array}$ & 20 & 30 & 42,5 & 7,5 \\
$\begin{array}{l}\text { Pemberian modul materi dan sarana pelatihan } \\
\text { lainnya sudah cukup baik }\end{array}$ & 55 & 40 & 5 & 0 \\
\hline
\end{tabular}

Tabel 1 menunjukkan bahwa untuk dalam hal terkait penyampaian materi oleh narasumber sangat menyenangkan, cukup menarik dan tidak membosankan sangat disetujui oleh para peserta pelatihan ini, namun terkait isi materi yang terlalu padat dan waktu pelatihan yang sangat singkat respon guru pun menyetujui, demikian adanya saran bahwa pelatihan harus berkelanjutan untuk diadakan Kembali karena antusias para peserta guru matematika. Sedangkan terkait Latihan/tugas guru dalam membuat applet guru lebih banyak kurang menyetujui kalua Latihan yang diberikan terlalu banyak atau menyita waktu mereka, hal ini membuktikan bahwa mereka senang dalam mengerjakan Latihan yang diberikan dan tidak merasa terbebani waktu dalam membuat applet sebagai tugas mereka.

Para pesertapun menyetujui bahwa pendampingan pelatih dan materi atau modul sudah cukup baik terlihat dari banyaknya presentase menyetujui dalam pelatihan ini serta pada hari kedua banyak guru matematika yang mempresentasikan hasil appletnya sesuai dengan materi yang disampaikan selanjutnya para pelatih memberikan feedback untuk hasil presentasinya, sehingga para peserta banyak yang menyukai pelatihan ini.

Namun, ada beberapa kesulitan para peserta dalam pembuatan applet pada geogebra, diantaranya adalah:

1. Sulit membuat gambar sesuai keinginan peserta

2. Masih belum menguasai tools dalam geogebra

3. Bingung dalam membuat lembar kerja di dalam geogebra online.

Hal ini tidak menjadi halangan peserta untuk tetap terus belajar dalam membuat applet di geogebra

\section{KESIMPULAN}

Kegiatan pengabdian kepada masyarakat ini secara umum berdampak pada peningkatan kompetensi guru matematika dalam membuat bahan ajar serta lembar kerja siswa di GeoGebra online di masa pandemi Covid-19 untuk dapat diterapkan dalam pembelajaran daring di sekolah para peserta. Kegiatan pelatihan ini memberikan pencerahan kepada guru matematika bahwa 
tidak harus selalu menggunakan papan tulis dalam hal menggambar, GeoGebra memudahkan guru matematika dalam hal menggambar sesuai dengan materi yang akan disampaikan di dalam kelas. Solusi yang ditawarkan pada pelatihan ini sangat tepat dan berguna bagi guru matematika selama proses PJJ di Sekolah sehingga dapat menyelesaikan masalah kesulitan guru dalam mengajar daring. Pembelajaran matematika akan lebih menyenangkan jika siswa mampu mengeksplorasi kemampuannya dengan menggunakan GeoGebra online serta dapat meningkatkan kemampuan pemahaman konsep yang baik dalam memahami materi matematika. Kegiatan pelatihan ini dapat dilanjutkan dengan tingkatan sekolah yang lebih tinggi yaitu sekolah menengah atas atau kejuruan agar semua para guru matematika baik tingkatan sekolah menengah pertama dan atas dapat membuat bahan ajar dan lembar kerja siswa dengan baik di GeoGebra online tanpa harus menggunakan LMS lainnya.

\section{UCAPAN TERIMA KASIH}

Ucapan terima kasih terutama ditujukan kepada Lembaga Pengabdian dan Pemberdayaan Masyarakat (LPPM) Universitas Muhammadiyah Prof. DR. HAMKA (UHAMKA) dengan nomor surat kontrak 0474/H.04.02/2020 yang telah memberikan kepercayaan dan pendanaan kepada penulis untuk melaksanakan kegiatan ini.

\section{DAFTAR PUSTAKA}

Alessandro, B. (2018). Digital Skills and Competence, and Digital and Online Learning. Turin: European Training Foundation.

Crews, J., \& Parker, J. (2017). The Cambodian Experience: Exploring University Students' Perspectives for Online Learning. Issues in Educational Research, 27(4), 697-719.

Darmayanti, N. W. S., Sadia, W., Studi, P., Sains, P., Sarjana, P. P., \& Ganesha, U. P. (2013). Pengaruh Model Collaborative Teamwork Learning terhadap Keterampilan Proses Sains dan Pemahaman Konsep Ditinjau dari Gaya Kognitif. E-Journal Program Pascasarjana Universitas Pendidikan Ganesha, 3(2).

Mather, M., \& Sarkans, A. (2018). Student Perceptions of Online and Face-to-Face Learning. International Journal of Curriculum and Instruction, 10(2), 61-76.

Muhson, A. (2010). Pengembangan Media Pembelajaran Berbasis Teknologi Informasi. Jurnal Pendidikan Akuntansi Indonesia, 8(2). https://doi.org/10.21831/jpai.v8i2.949

Mustofa, Z., Sutopo, S., Mufti, N., \& Asmichatin, A. (2019). The Impact of Modeling Instruction Based on System Toward Work-Energy Concept Understanding. Jurnal Penelitian \& Pengembangan Pendidikan Fisika, 5(2).

Nasrulloh, I., \& Ismail, A. (2018). Analisis Kebutuhan Pembelajaran Berbasis Ict. Jurnal Petik, 3(1), 28. https://doi.org/10.31980/jpetik.v3i1.355

Pilkington, O. A. (2018). Active Learning for an Online Composition Classroom: Blogging as an Enhancement of Online Curriculum. Journal of Educational Technology Systems, 47(2), 1-14. https://doi.org/https://doi.org/10.1177/0047239518788278

Putrawansyah, Ferry, Zulkardi, \& Sardianto. (2016). Pengembangan Digital Book Berbasis Android Materi Perpindahan kalor di Sekolah Menengah Atas. Indonesian Journal on Networking and Security, 5(4).

Riaz, A. (2018). Effects of Online Education on Encoding and Decoding Process of Students and Teachers. International Conference E-Learning, 42-48. https://files.eric.ed.gov/fulltext/ED590288.pdf. 